\title{
Macrophage-specific Expression of Human Apolipoprotein E Reduces Atherosclerosis in Hypercholesterolemic Apolipoprotein E-null Mice
}

\author{
Stefano Bellosta, * Robert W. Mahley, ${ }^{\star \ddagger \S}$ David A. Sanan, ${ }^{\star \star}$ Jennifer Murata, * Dale L. Newland, * John M. Taylor, ${ }^{\star \ddagger}$ \\ and Robert E. Pitas* *\# \\ * Gladstone Institute of Cardiovascular Disease, ${ }^{\ddagger}$ Cardiovascular Research Institute, Departments of ${ }^{\S}$ Medicine, "Pathology, and \\ 'Physiology, University of California, San Francisco, California 94141-9100
}

\begin{abstract}
apoE deficiency causes hyperlipidemia and premature atherosclerosis. To determine if macrophage-specific expression of apoE would decrease the extent of atherosclerosis, we expressed human apoE in macrophages of apoE-null mice $\left(a p o E^{-1-}\right)$ and assessed the effect on lipid accumulation in cells of the arterial wall. Macrophage-specific expression of human apoE in normal mice was obtained by use of the visna virus LTR. These animals were bred with $a p o E^{-1-}$ mice to produce animals hemizygous for expression of human apoE in macrophages in the absence of murine apoE $\left(a p o E^{-1-}, h T g E^{+/ 0}\right)$. Low levels of human apoE mRNA were present in liver and spleen and high levels in lung and peritoneal macrophages. Human apoE was secreted by peritoneal macrophages and was detected in Kupffer cells of the liver. Human apoE in the plasma of $a p o E^{-/-}, h \mathrm{TgE}^{+/ 0}$ mice $(n$ $=30)$ was inversely correlated $(P<0.005)$ with the plasma cholesterol concentration. After 15 wk on a normal chow diet, atherosclerosis was assessed in $a p o E^{-1-}, h \mathrm{TgE}^{+/ 0}$ animals and in $a p o E^{-1-}, h T g E^{0 / 0}$ littermates matched for plasma cholesterol level $(\sim 450 \mathrm{mg} / \mathrm{dl})$ and lipoprotein profile. There was significantly less atherosclerosis in both the aortic sinus and in the proximal aorta $(P<0.0001)$ in the animals expressing the human apoE transgene. In apo$E^{-/-}, \boldsymbol{h T g E} E^{+/ 0}$ animals, which had detectable atherosclerotic lesions, human apoE was detected in the secretory apparatus of macrophage-derived foam cells in the arterial wall. The data demonstrate that expression of apoE by macrophages is antiatherogenic even in the presence of high levels of atherogenic lipoproteins. The data suggest that apoE prevents atherosclerosis by promoting cholesterol efflux from cells of the arterial wall. (J. Clin. Invest. 1995. 96:21702179.) Key words: apoE deficiency • atherogenesis • hyperlipidemia $\cdot$ lipoproteins $\cdot$ transgenic mice
\end{abstract}

\section{Introduction}

apoE is a $34,000-$ molecular weight protein that plays a central role in maintaining plasma cholesterol homeostasis (1). apoE

Address correspondence to Robert E. Pitas, The Gladstone Institutes, P. O. Box 419100, San Francisco, CA 94141-9100. Phone: 415-8267500; FAX: 415-285-5632. Stefano Bellosta's current address is Institute of Pharmacological Science, University of Milan, Via Balzaretti 9 , 20133 Milan, Italy.

Received for publication 7 April 1995 and accepted in revised form 4 August 1995

J. Clin. Invest.

(C) The American Society for Clinical Investigation, Inc.

$0021-9738 / 95 / 11 / 2170 / 10 \$ 2.00$

Volume 96, November 1995, 2170-2179 mediates the binding of lipoproteins to the LDL receptor and to the LDL receptor-related protein $(1,2)$, and it is required for the clearance of chylomicron remnants, VLDL, intermediate density lipoproteins, and a subclass of HDL from the plasma (3-7).

The majority of plasma apoE is derived from the liver (8), where it is synthesized primarily by hepatocytes (1). Apolipoprotein $\mathrm{E}$ is also synthesized by macrophages in various tissues, including Kupffer cells in the liver $(9,10)$. Apolipoprotein E is abundant in both human and rabbit atherosclerotic lesions, where it is produced by macrophages (11), but the role of apoE in the atherosclerotic lesion and whether it is proatherogenic or antiatherogenic are unknown. The apoE-mediated uptake of lipoproteins by cells of the arterial wall may lead to lipid accumulation and foam cell formation. Alternatively, apoE may function in reverse cholesterol transport, contributing to the removal of cholesterol from lipid-rich foam cells for delivery to the liver $(1,12,13)$. Support for both theories has been obtained in in vitro studies.

Apolipoprotein E-null ( $\left.a p o E^{-1-}\right)$ mice have been generated recently by gene targeting (14-16). These animals develop pronounced hypercholesterolemia on a normal chow diet, with a prominent increase in the level of VLDL and a decrease in the level of HDL $(15,16)$. The mice develop foam cell-rich fatty lesions in the aortic sinus and proximal aorta by 3 mo of age $(16,17)$, and after $8-9 \mathrm{mo}$, fibrous lesions are present $(17$, 18). The atherosclerotic lesions in these mice have features characteristic of those seen in humans and other species, including both proliferating smooth muscle cells and calcium deposits (17-22). These mice provide a unique model in which to test the impact of cell-specific expression of apoE on atherogenesis.

Recent studies have addressed the role of apoE, produced in the arterial wall by macrophages or other cell types, on the development of atherosclerosis in mice. Linton et al. (23) have reconstituted the expression of murine apoE by macrophages after bone marrow transplantation in $a p o E^{-/-}$mice whose original bone marrow was lethally irradiated. The expression of murine apoE by macrophages both normalized plasma lipid levels and prevented the normal development of atherosclerosis seen in the apoE-deficient animals. Shimano et al. (24) generated transgenic mice that expressed human apoE in cells of the arterial wall and in many other tissues of C57BL/6 mice. Atherosclerosis was reduced in the transgenic animals even though plasma lipid levels were not altered, suggesting that enhanced production of apoE in these animals was antiatherogenic (24). The results of these studies, however, do not define the effect of macrophage-derived apoE on atherosclerosis. In the study by Linton et al. (23), the marked reduction in plasma cholesterol after bone marrow transplantation undoubtedly contributed to the decrease in atherosclerosis, and in the study (24) by Shimano et al., the reduction in lesion formation was due to ectopic production of apoE by endothelial and smooth muscle 


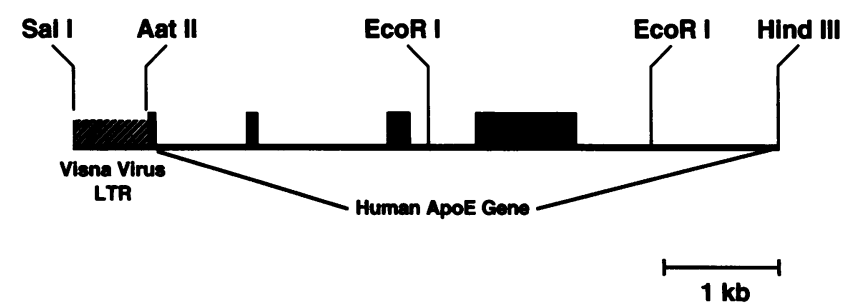

Figure 1. Schematic representation of the human apoE gene construct LTR-APOE, used to produce the transgenic mice expressing human apoE in macrophages.

cells that do not normally express this apolipoprotein and by the liver.

The aim of this study was to determine the effect of the production of apoE by macrophages on the development of atherosclerosis in transgenic mice. Human apoE expression was directed to macrophages of murine $a p o E^{-1-}$ animals, and the effect on atherosclerosis was assessed. The expression of human apoE in macrophages markedly reduced atherosclerosis in comparison to that observed in $a p o E^{-1-}, h T g E^{0 / 0}$ littermates matched for serum cholesterol levels and lipoprotein profile. Our results demonstrate a direct protective effect of apoE on arterial wall lipid accumulation that is independent of its plasma lipid-lowering effects.

\section{Methods}

Production and screening of transgenic mice. Human apoE expression was directed to macrophages by the sheep visna virus long terminal repeat (LTR). ${ }^{1}$ A fragment containing the LTR was generated from the pVISLTRCAT construct, a gift of Janice Clements, Johns Hopkins University, Baltimore, MD, described by Small et al. (25), by PCR cloning. At the 5 ' end of the LTR, an oligonucleotide complementary to 24 bases beginning 203 nucleotides upstream from the U3 element of the LTR (26) was prepared. Extra sequences for SalI and ClaI restriction endonuclease recognition were included at the $5^{\prime}$ terminus of the primer. At the 3' end of the LTR, an oligonucleotide complementary to 24 nucleotides that terminates 8 nucleotides downstream from the U5 element of the LTR (27) was prepared. The sequence for AatII recognition was included at the $3^{\prime}$ terminus of the primer. The PCRcloned LTR (containing 622 nucleotides of viral sequence) was ligated to the AatII site in the first exon of the complete human apoE gene (3.6 $\mathrm{kb}$ in length), followed by $1.7 \mathrm{~kb}$ of 3 ' flanking sequence that terminated at a HindIII site. The completed construct was inserted into the polylinker of pBSSK (Stratagene Inc., La Jolla, CA) at its SalI and HindIII sites for subsequent DNA preparation. A map of the PLTR-APOE expression vector is presented in Fig. 1. A 5.9-kb fragment of LTRAPOE was cut with SalI and HindIII, electrophoresed on an agarose gel, purified from the gel by electroelution, and injected into pronuclei of one-cell ICR mouse embryos, as described (28). Transgenic founder pups were identified by Southern blotting of tail-tip DNA $(28,29)$. One of the founders that expressed significant quantities of human apoE in macrophages was used to develop a transgenic line for the breeding studies.

To generate the study population, murine apoE-null mice (apo$\left.E^{-/-}\right)($C57BL $/ 6 \times 129 /$ J hybrids), provided by Dr. N. Maeda (University of North Carolina, Chapel Hill, NC) $(14,16)$, were crossed with transgenic ICR mice homozygous for the expression of human apoE in macrophages $\left(h \mathrm{TgE}^{+/+}\right)$. The $\mathrm{F} 1$ mice, which were hemizygous for the human apoE transgene and heterozygous for the knockout mutation

1. Abbreviation used in this paper: LTR, long terminal repeat. $\left(a p o E^{+/-}, h T g E^{+/ 0}\right)$ after this initial cross, were backcrossed to apoEnull mice. Theoretically, $25 \%$ of the F2 progeny should lack mouse apoE $\left(a p o E^{-1-}\right)$ and be hemizygous for the human apoE transgene $\left(h \mathrm{TE}^{+/ 0}\right)$. These $\mathrm{F} 2$ animals then were intercrossed to obtain mice homozygous for the absence of murine apoE and hemizygous for the human transgene $\left(\mathrm{apoE}^{-/-}, h \mathrm{TgE}^{+/ 0}\right)$ or homozygous $\left(\mathrm{apoE}^{-/-}, h \mathrm{TgE}^{+1}\right.$ ${ }^{+}$) for the expression of human apoE by macrophages. Thus, mice used in this study were genetic hybrids of strains C57BL/6, 129/J, and ICR. Mice were genotyped by Southern blotting. The mice were fed normal laboratory mouse chow diet (Purina 5058; Ralston Purina Co., St. Louis, MO) containing $9 \%$ fat and $0.02 \%$ cholesterol.

Southern blot analysis. Tail-tip DNA was purified (28), digested with EcoRI, electrophoresed on a $1 \%$ agarose gel, transferred to nitrocellulose, and hybridized with a ${ }^{32} \mathrm{P}$-labeled human apoE cDNA probe (29). Intact copies of the human apoE transgene were indicated by the presence of a 1.9-kb band. Genotyping of apoE-null mice was as described (14).

$R$ Nase protection assay. The expression of the transgene by macrophages was confirmed by RNase protection assay and Western blotting $(23,30)$. Total RNA was extracted from mouse tissues and macrophages using the Totally RNA Kit (Ambion Inc., Austin, TX). A 192-base antisense RNA probe for human apoE mRNA was transcribed, using bacteriophage T3 RNA polymerase in the presence of $\left[{ }^{32} \mathrm{P}\right] \mathrm{UTP}$, from a human apoE cDNA fragment (corresponding to bases 217-411 of the human apoE cDNA) that had been cloned in Bluescript vector (Stratagene Inc.), as described (31). Hybridization of $5 \mu \mathrm{g}$ of the tissue RNA with $2 \times 10^{5} \mathrm{cpm}$ of labeled probe was carried out using the Ribonuclease Protection Assay Kit II (Ambion Inc.). The protected fragments were analyzed on $6 \%$ polyacrylamide gels containing $8 \mathrm{M}$ urea. The gels were dried and exposed overnight to photographic film at $-70^{\circ} \mathrm{C}$. RNA from the human hepatoma cell line HepG2 served as a positive control, and RNA from an $a p o E^{-/-}, h T g E^{0 / 0}$ mouse served as a negative control. As a control for the integrity of the RNA and to ensure equivalent concentrations, $1 \mu \mathrm{g}$ of total RNA from each organ was subjected to $1 \%$ agarose gel electrophoresis and stained with ethidium bromide.

Immunocytochemistry. Immunolocalization of apoE in macrophages was achieved by indirect immunofluorescence. Briefly, peritoneal macrophages were harvested from thioglycolate-stimulated mice by peritoneal lavage with PBS and adhered to poly-L-lysine-coated slides for $30 \mathrm{~min}$. All steps in the following protocol were carried out at room temperature unless otherwise specified. The slides with adherent macrophages were gently rinsed in PBS and then fixed overnight at $4^{\circ} \mathrm{C}$ with 3\% paraformaldehyde in PBS. After two 5-min washes in PBS, the macrophages were permeabilized for $4 \mathrm{~min}$ in PBS containing $0.1 \%$ Triton X-100. Excess aldehyde was quenched for $10 \mathrm{~min}$ with $0.05 \mathrm{M}$ ammonium chloride and nonspecific binding sites blocked for $30 \mathrm{~min}$ with 3\% BSA in PBS. The primary antibody, rabbit antiserum against human apoE diluted 1:1,000 in PBS containing 1\% BSA, was incubated with the cells for $45 \mathrm{~min}$. The slide was washed and exposed for $45 \mathrm{~min}$ to secondary antibody, FITC-conjugated goat anti-rabbit IgG (Zymed Laboratories, Inc., South San Francisco, CA) at $10 \mathrm{mg} / \mathrm{ml}$ in PBS with $1 \%$ BSA. Slides were washed, and macrophages were coverslipmounted using DABCO (2.3\% 1,4-diazobicyclo-(2,2,2)-octane) in PBS containing $90 \%$ glycerol. Images were captured by laser-scanning confocal microscopy using the BHS filter block (excitor 488DF10, dichroic 510LP, emission 515LP) on the MRC-600 system (Bio-Rad, Hercules, CA).

For immunolocalization of apoE and macrophages in tissue sections, mice at $15 \mathrm{wk}$ of age were euthanized and perfusion-fixed with $3 \%$ paraformaldehyde in PBS. The tissues were excised and snap-frozen in liquid nitrogen prior to embedding in Tissue-Tek OCT compound (Miles, Inc., Elkhart, IN). Frozen sections were cut on a Reichert 2800 cryostat (Reichert Scientific Instruments, Buffalo, NY). Once adhered to slides, sections were immunostained for apoE as detailed above for isolated macrophages

Macrophages were detected in adjacent serial sections of atherosclerotic lesions by immunolocalization of $\mathrm{F} 4 / 80$ antigen, a sensitive and specific marker for mature murine macrophages (32). Nonpermeabil- 
ized cryostat sections were washed twice with PBS, once with $0.05 \mathrm{M}$ ammonium chloride for $10 \mathrm{~min}$, and incubated for $30 \mathrm{~min}$ in PBS with $3 \%$ BSA. The rat monoclonal antibody F4/80, against a plasma membrane glycoprotein in murine macrophages (BioSource International, Camarillo, CA), was diluted 1:20 in PBS-glycine containing 1\% BSA and incubated with the sections overnight at $4^{\circ} \mathrm{C}$. The slides were washed and then exposed for $1 \mathrm{~h}$ at $37^{\circ} \mathrm{C}$ to biotinylated sheep antirat Ig (Amersham Corp., Arlington Heights, IL) diluted 1:200 in PBSglycine containing 5\% normal goat serum and $1 \%$ BSA. Slides were washed exhaustively before incubation for $1 \mathrm{~h}$ at $37^{\circ} \mathrm{C}$ with fluoresceinlabeled streptavidin (Amersham Corp.) diluted 1:2,500 in PBS-glycine containing $1 \%$ BSA. Thereafter, slides were prepared for confocal microscopy as described for the immunocytochemistry of human apoE. Tissues were examined using the GHS filter block (excitor 514DF10, dichroic DR540LP, emission 550LP) with the MRC-600 laser scanning confocal microscope.

Expression of apoE by macrophages in culture. Mice were given a $3-\mathrm{ml}$ intraperitoneal injection of $4 \%$ thioglycolate in water. After $3 \mathrm{~d}$, macrophages were harvested by peritoneal lavage with PBS, plated at a density of $3.0 \times 10^{6}$ cells $/ 35-\mathrm{mm}$ dish, and allowed to adhere to dishes for $3 \mathrm{~h}$ in DME containing $10 \%$ fetal bovine serum. The cell monolayers were washed three times with serum-free DME and incubated for $24 \mathrm{~h}$ with DME containing $10 \%$ fetal bovine serum, and then for an additional $24 \mathrm{~h}$ in DME containing $0.2 \%$ BSA.

The media from the second 24-h incubation were collected, and, after $100 \mu \mathrm{g} / \mathrm{ml}$ of phenylmethylsulfonyl fluoride and $5 \mu \mathrm{g} / \mathrm{ml}$ of leupeptin were added, centrifuged to eliminate suspended cells. To precipitate the secreted apoE, fumed silica (Sigma Chemical Co., St. Louis, MO) was added to the conditioned media (final concentration $1.5 \mathrm{mg}$ / $\mathrm{ml}$ ) and centrifuged at $13,000 \mathrm{~g}$ for $10 \mathrm{~min}$ (30). Each pellet was washed three times with sterile water and dissolved in gel-loading buffer containing 2-mercaptoethanol. Samples were electrophoresed on 5-20\% polyacrylamide gradient gels containing SDS, as previously described (30). Proteins were transferred to nitrocellulose paper by semidry blotting (30) and incubated with either anti-human apoE or anti-mouse apoE polyclonal antisera (1:1,000 dilution) raised in rabbit (generously provided by Dr. K. H. Weisgraber, Gladstone Institute of Cardiovascular Disease, San Francisco, CA). The bound primary antibodies were detected using donkey anti-rabbit secondary antibody conjugated to horseradish peroxidase (1:5,000 dilution) (Amersham Corp.) and an Enhanced Chemiluminescence kit (Amersham Corp.), according to the manufacturer's instructions. The amount of apoE secreted by the cells was quantitated by densitometric scanning (Ambis Scanner, San Diego, CA ) using standards of authentic human or mouse apoE electrophoresed on the same gel (33).

Lipid and lipoprotein analyses. Analyses were performed on littermates after a 4-h fast. Blood was drawn into tubes containing EDTA. Plasma cholesterol and triglyceride concentrations were measured using Boehringer-Mannheim Biochemicals (Indianapolis, IN) enzymatic assay kits (34). Plasma human apoE concentration was measured by Western blotting. $2 \mu \mathrm{l}$ of plasma were electrophoresed on 5-20\% polyacrylamide gradient gels containing SDS. The proteins were then transferred to nitrocellulose paper and the amount of apoE measured, as described above. Purified human plasma apoE was used as a standard for quantitation (33).

To determine the plasma lipoprotein profile, $100 \mu \mathrm{l}$ of plasma was applied to a Superose 6 column (FPLC system, Pharmacia, Uppsala, Sweden) and eluted with $1 \mathrm{mM}$ EDTA in PBS, pH 7.4, at a constant flow rate of $0.4 \mathrm{ml} / \mathrm{min}(34,35)$. Fractions $(0.5 \mathrm{ml})$ were collected and cholesterol and triglyceride concentrations measured enzymatically (34).

Lesion area measurement. After a 4-h fast, 15-wk-old mice were anesthetized with Metofane (methoxyflurane) (Pitman-Moore, Inc., Mundelein, IL). After perfusion fixation with $10 \%$ neutral buffered formalin, the heart, together with the thoracic aorta, was removed from the animals and processed as previously described (36). Sections were stained with Oil Red $\mathrm{O}$, and lesions were quantified using the computerized system, Image I (36).

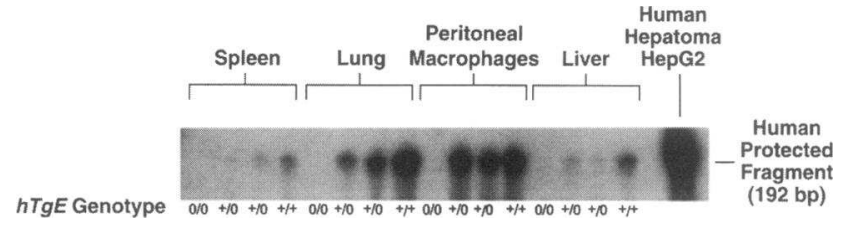

Figure 2. Ribonuclease protection assay showing the expression of human apoE mRNA in tissues of transgenic mice. Total RNA was isolated from the indicated tissues of mice that were homozygous for the apoE knockout mutation and had the indicated genotype for the human apoE transgene. Total RNA from the human hepatoma cell line HepG2 served as positive control.

\section{Results}

Production and characterization of transgenic animals. Transgenic mice expressing human apoE in macrophages were produced by expressing apoE under the control of the visna virus LTR, which has been used previously to direct the expression of a reporter gene specifically in macrophages of transgenic mice (25). Each animal possessed one copy of the human apoE gene. To determine the effect of macrophage expression of apoE on serum lipid levels and on the development of atherosclerosis, these animals homozygous for the human apoE transgene $\left(h \mathrm{TgE}^{+/+}\right)$were crossed with murine apoE-null mice (apo$E^{-1-}$ ), which develop spontaneous hypercholesterolemia and atherosclerosis on a normal chow diet $(15,16)$. The progeny were backcrossed to the apoE-null mice to produce mice (25\%) that did not express murine apoE but were hemizygous for the expression of human apoE by macrophages $\left(a p o E^{-/-}, h T g E^{+/ 0}\right)$. These animals were then intercrossed. The litters obtained from this final mating contained apoE-null mice that did not express human apoE $\left(a p o E^{-/-}, h T g E^{o / o}\right.$, which were used as control mice) and mice hemizygous $\left(a p o E^{-1-}, h T g E^{+/ 0}\right.$ ) or homozygous $\left(a p o E^{-/-}, h T g E^{+/+}\right)$for the expression of human apoE by macrophages.

Sites of apoE production in mice were detected using RNase protection assays and immunofluorescence microscopy. All of the animals lacked mouse apoE mRNA, and all of the control $a p o E^{-/-}, h T g E^{0 / 0}$ mice lacked human apoE (Fig. 2). Human apoE mRNA was detected at relatively high levels in peritoneal macrophages and lung and at lower levels in the liver and spleen of the $a p o E^{-1-}, h T g E^{+/ 0}$ and $a p o E^{-1-}, h T g E^{+/+}$animals but not in the $a p o E^{-/-}, h T g E^{0 / 0}$ mice (Fig. 2). As expected, the mice homozygous for the human transgene showed an increased signal as compared with that seen in mRNA from hemizygous animals.

Macrophage production of human apoE was confirmed by immunocytochemistry. Intense immunoreactivity for human apoE was detected in peritoneal macrophages from the transgenic animals but not in control macrophages (Fig. 3). The apoE was present as intense unipolar juxtanuclear fluorescence, which represents apoE in the Golgi apparatus, indicating that apoE is a secreted protein (Fig. 3, $A$ and $B$ ). To a lesser extent, apoE immunolocalized in a cytoplasmic punctate pattern may represent apoE in secretory vesicles or endosomes (Fig. 3). The level of secretion of human apoE by mouse peritoneal macrophages was examined directly by analysis of conditioned medium from the cells on Western blots. The macrophages from the mice expressing the human apoE $\left(a p o E^{-/-}, h T_{g E^{+/ 0}}\right.$ and $a p o E^{-/-}, h \mathrm{TgE}^{+/+}$) secreted low levels of apoE compared to the amount of apoE secreted from the macrophages of a non- 

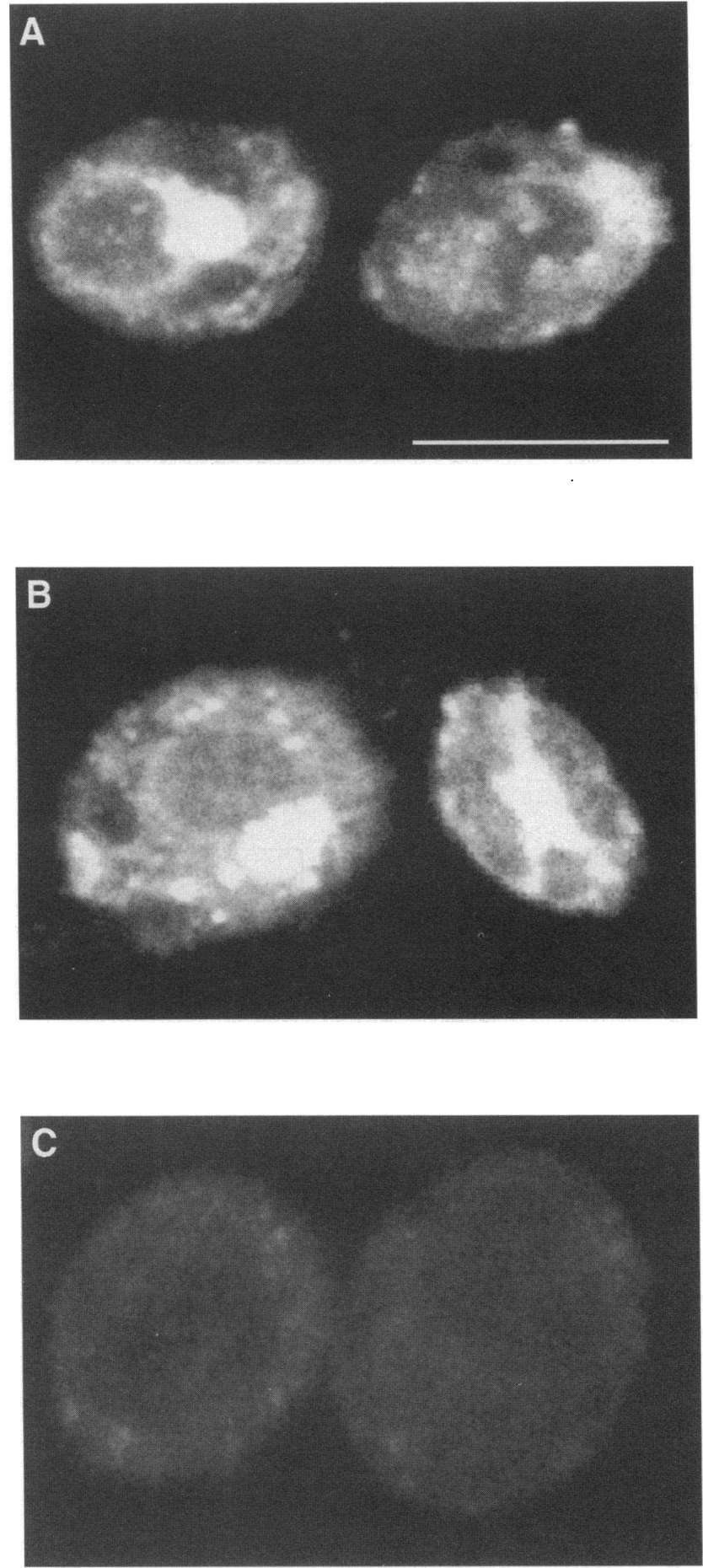

Figure 3. Confocal fluorescence microscopy showing the expression of human apoE by macrophages from apoE $E^{-/-}, h T g E^{+/ 0}(A)$ and apo$E^{-/-}, h T g E^{+/+}$mice $(B)$ and the lack of expression by macrophages obtained from $a p o E^{-/-}, h T g E^{0 / 0}$ mice $(C)$, which were used as negative controls. Indirect immunofluorescence was performed with an antibody specific for human apoE as described in Methods. Note the unipolar juxtanuclear fluorescence, indicative of apoE immunolocalization in the Golgi apparatus and endoplasmic reticulum. The punctate cytoplasmic fluorescence may be endosomal or from secretory vesicles. (Bar $=10$ $\mu \mathrm{m}$ and refers to all figures.)

transgenic C57BL/6 mouse. The human apoE secreted was 3$8 \%$ of the level of mouse apoE (Table I), and it comigrated with authentic human apoE by electrophoresis on polyacrylamide gels (data not shown).
Table I. Secretion of apoE from Mouse Peritoneal Macrophages

\begin{tabular}{lcc}
\hline & \multicolumn{2}{c}{ apoE secreted* } \\
\cline { 2 - 3 } & Mouse & Human \\
\hline & \multicolumn{2}{c}{$\mu g / m g$ of cell protein } \\
C57BL/6 (nontransgenic) & 2.06 & - \\
apoE $^{-/-}, \mathrm{hTgE}^{+/}$ & - & 0.06 \\
apoE $^{-/}, h T g E^{+/ 0}$ & - & 0.13 \\
apoE $^{-/-}, h T g E^{+/+}$ & - & 0.16 \\
apoE $^{-/-}, h T g E^{+/+}$ & - & 0.16 \\
\hline
\end{tabular}

* Cells were isolated from thioglycolate-stimulated animals and incubated for $24 \mathrm{~h}$ at $37^{\circ} \mathrm{C}$ in DME containing $0.2 \%$ BSA. The medium was then collected, and the amount of apoE secreted was measured as described in Methods. ${ }^{\ddagger}$ Each value is the mean of two separate experiments. The duplicates did not differ by more than $10 \%$.

The visna virus LTR has previously been reported to direct the expression of a reporter construct both by macrophages and by spleen lymphocytes (25). We prepared spleen lymphocytes as described (25) and examined the medium for the presence of apoE. In two independent experiments using spleens from two animals that expressed apoE in peritoneal macrophages, we did not detect expression of apoE by lymphocytes.

The tissue distribution of the human apoE mRNA in lung and spleen is consistent with macrophage expression. In the liver, human apoE was detected by immunocytochemistry in individual cells present in the sinusoids, suggesting by their pattern and location that they were Kupffer cells (data not shown). However, a low level of hepatocyte expression could not be ruled out. The apoE was not detected in sinusoidal endothelial cells.

Effect of human apoE on lipids and lipoprotein profile in apoE-null mice. To determine the impact of the secretion of human apoE by the macrophages on plasma lipid levels, blood was drawn from 15-wk-old mice, and total plasma cholesterol and triglyceride levels were determined. The expression of human apoE by macrophages reduced plasma cholesterol levels substantially, in a gene dose-dependent manner (Table II). By

Table II. The Effect of Expression of Human apoE by Macrophages on Plasma Cholesterol and Triglyceride Concentrations in Murine apoE-null Mice

\begin{tabular}{|c|c|c|}
\hline \multirow[b]{2}{*}{ Mice } & \multicolumn{2}{|c|}{ Plasma* } \\
\hline & Cholesterol & Triglycerides \\
\hline & \multicolumn{2}{|c|}{$m g / d l^{\ddagger}$} \\
\hline$a p o E^{-1-}, h T g E^{0 / 0}(n=31)$ & $593 \pm 157$ & $194 \pm 108$ \\
\hline$a p o E^{-1-}, h T g E^{+/}(n=39)^{\S}$ & $408 \pm 126^{\prime \prime}$ & $184 \pm 125$ \\
\hline$a p o E^{-/-}, h T g E^{+/+}(n=7)^{\S}$ & $236 \pm 98^{\| 1}$ & $144 \pm 60$ \\
\hline
\end{tabular}

* Blood was drawn from 15-wk-old mice after a 4-h fast. Plasma cholesterol and triglyceride levels were measured as described in Methods.

${ }^{\ddagger}$ Data are reported as the mean \pm SD for the number of animals indicated. ${ }^{8}$ The animals heterozygous and homozygous for expression of human apoE in macrophages did not express murine apoE. The animals were generated as described in Methods. "P<0.01 vs $a p o E^{-1-}, h T g E^{o r}$. $i_{P}<0.025$ vs apoE $E^{-1-}, h T_{g} E^{+\infty}$. 


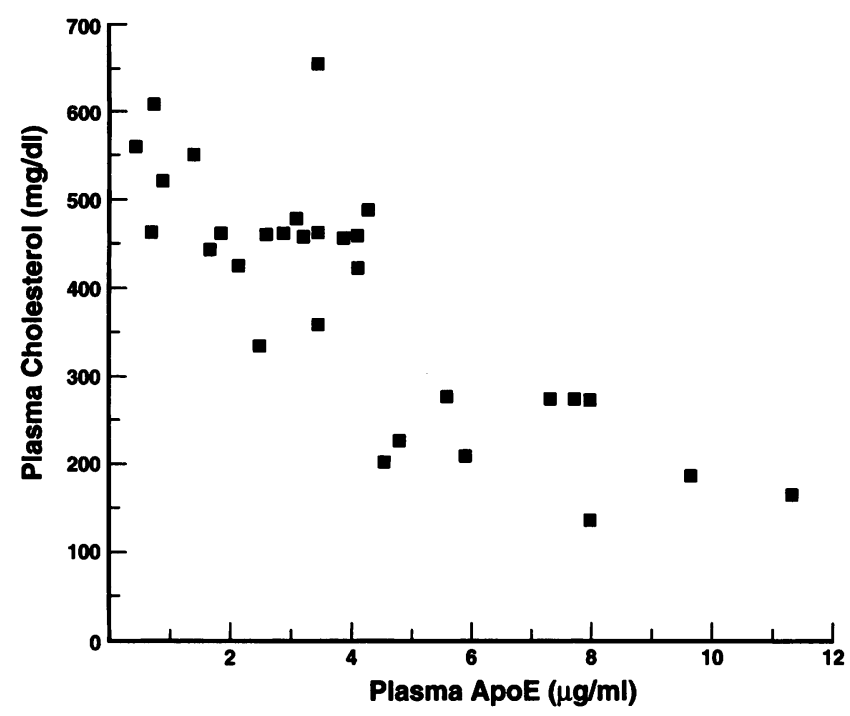

Figure 4. Inverse correlation between plasma cholesterol levels and plasma human apoE concentration in $a p o E^{-/-}, h \mathrm{TgE}^{+/ 0}$ mice expressing human apoE in macrophages. Plasma cholesterol and human apoE concentrations in 15-wk-old mice were measured on blood obtained after a 4-h fast, as described in Methods. $r^{2}=0.668, P<0.005$ using a onetailed test.

comparison to apoE-null littermate controls $a p o E^{-/-}, h T g E^{0 / 0}$ (not expressing human apoE), plasma total cholesterol levels in $a p o E^{-/-}, h T g E^{+/ 0}$ animals were reduced by $\sim 31 \%$, whereas in the apoE $E^{-1-}, h \mathrm{TgE}^{+/+}$mice, the levels dropped by $60 \%$. There was no effect of expression of human apoE on plasma triglyceride concentrations in the $a p o E^{-/}, h \mathrm{TgE}^{+/ 0}$ animals or in the $a p o E^{-/-}, h \mathrm{TgE}^{+/+}$mice (Table II).

To determine if the reduction in plasma cholesterol levels was directly proportional to the amount of human apoE in the plasma, the plasma apoE concentration was determined in 30 apoE $E^{-1-}, h T g E^{+/ 0}$ mice. In these animals, human apoE in the plasma varied from $\sim 0.2-11.0 \mu \mathrm{g} / \mathrm{ml}$ and plasma cholesterol from $\sim 200-650 \mathrm{mg} / \mathrm{dl}$. There was a clear inverse relationship between the concentration of apoE and plasma cholesterol levels, $P<0.005$ (Fig. 4). Animals with the highest plasma apoE concentration had the lowest plasma cholesterol. As expected, none of the animals had any detectable mouse apoE in their plasma (data not shown). The reason for the wide range in plasma apoE levels is unknown; however, it is likely to result from the genetic heterogeneity of the animals.

Effect of human apoE production on atherosclerosis in apoE-null mice. We considered that apoE production by macrophages might result in reduced lipid deposition in the arterial wall of the apoE-null mice. To explore this postulate, we examined the extent of atherosclerosis in $15 \mathrm{apoE}^{-/-}, h \mathrm{TgE} \mathrm{E}^{0 / 0}$ mice (eight females and seven males) not expressing human apoE and in $13 \mathrm{apoE}^{-1-}, h \mathrm{TgE}^{+/ 0}$ mice (six females and seven males) that were selected on the basis of similar levels of total plasma cholesterol (Table III). The plasma cholesterol concentrations in the $a p o E^{-1-}, h T g E^{o / 0}$ mice selected for the atherosclerosis study ranged from 325 to $555 \mathrm{mg} / \mathrm{dl}$ and, in the apo$E^{-/-}, h T g E^{+/ 0}$ mice, from 334 to $551 \mathrm{mg} / \mathrm{dl}$. The plasma level of human apoE in the $a p o E^{-/-}, h T g E^{+/ 0}$ mice studied ranged between 2 and $4 \mu \mathrm{g} / \mathrm{ml}$, which is $<7 \%$ of the level of the normal mouse plasma apoE concentration $(60-80 \mu \mathrm{g} / \mathrm{ml})(37)$.

The animals were maintained for $15 \mathrm{wk}$ on a normal labora-
Table III. Plasma Cholesterol and Triglyceride Concentrations of Mice* that Were Used to Examine the Development of Atherosclerosis

\begin{tabular}{ccc}
\hline & \multicolumn{2}{c}{ Plasma $^{\ddagger}$} \\
\cline { 2 - 3 } Mice & Cholesterol & Triglycerides \\
\hline & & $m g / d l^{s}$ \\
apoE $^{-/-}, h T g E^{00}(n=15)$ & $482 \pm 62$ & $173 \pm 67$ \\
apoE $^{-1-}, h T g E^{+/ 0}(n=13)^{\| 1}$ & $449 \pm 70$ & $153 \pm 54$ \\
\hline
\end{tabular}

* Apolipoprotein E-null mice and littermates hemizygous for the expression of human apoE in macrophages. ${ }^{\ddagger}$ Plasma was obtained from 15 -wk-old animals fasted for $4 \mathrm{~h}$ and lipid determinations performed as described in Methods. ${ }^{8}$ The data are reported as the mean \pm SD. "The animals expressing human apoE in macrophages did not express murine apoE, as described in the legend to Table I and in Methods.

tory chow diet. The plasma lipoprotein profiles in the apo$E^{-/-}, h T g E^{0 / 0}$ mice and the $a p o E^{-/-}, h T g E^{+/ 0}$ animals were examined by FPLC. A comparison of the elution profiles of the two groups is shown in Fig. 5. The distributions of plasma cholesterol (Fig. $5 A$ ) and triglyceride (Fig. $5 B$ ) among the
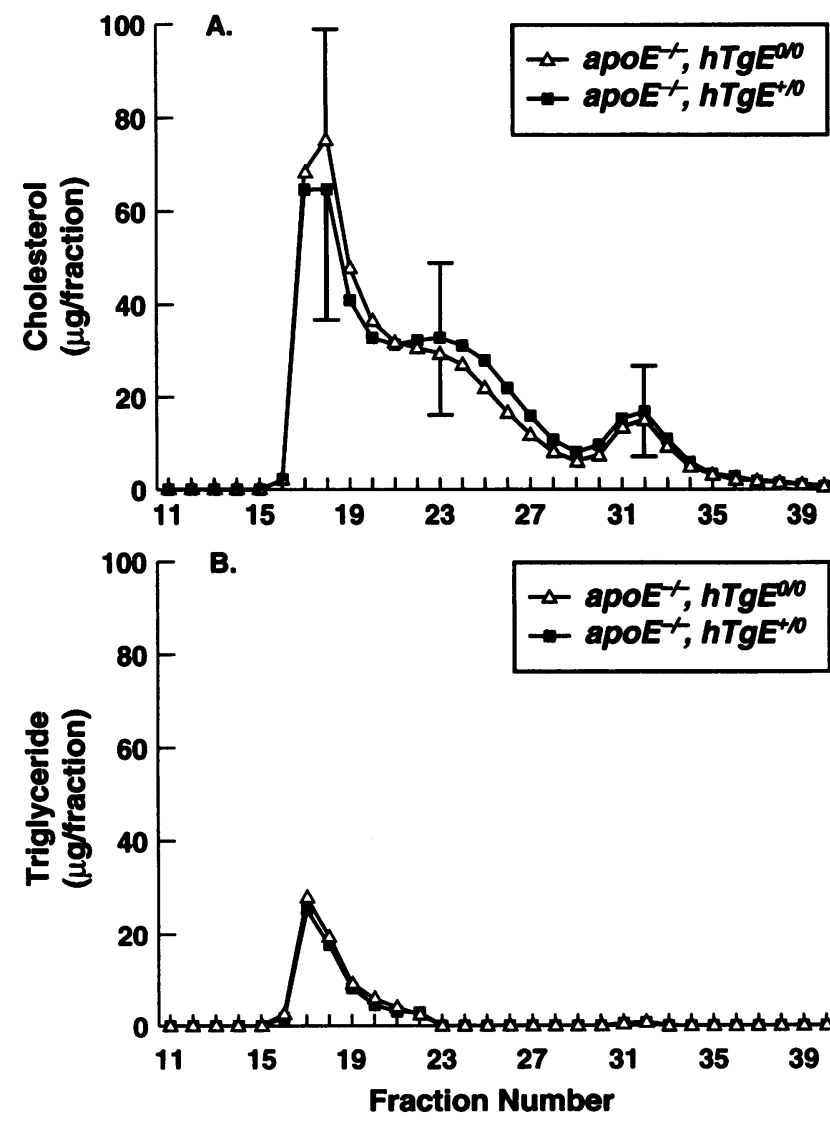

Figure 5. Superose 6 chromatography was performed on $100 \mu 1$ of fasting plasma drawn from $a p o E^{-1-}, h T g E^{0 / 0}$ mice $(\triangle)$ and apo$E^{-1-}, h T g E^{+/ 0}$ mice ( $(\square)$. Cholesterol $(A)$ and triglyceride $(B)$ concentrations in the FPLC fractions were determined as described in Methods The values represent the mean from $15 \mathrm{apoE}^{-/-}, h \mathrm{TgE}^{0 / 0}$ and $13 \mathrm{apo}$ $E^{-/-}, h T g E^{+/ 0}$ mice. The mean plasma total cholesterol and triglyceride levels are reported in Table III. Representative SD bars are shown for the VLDL, LDL, and HDL peaks. 


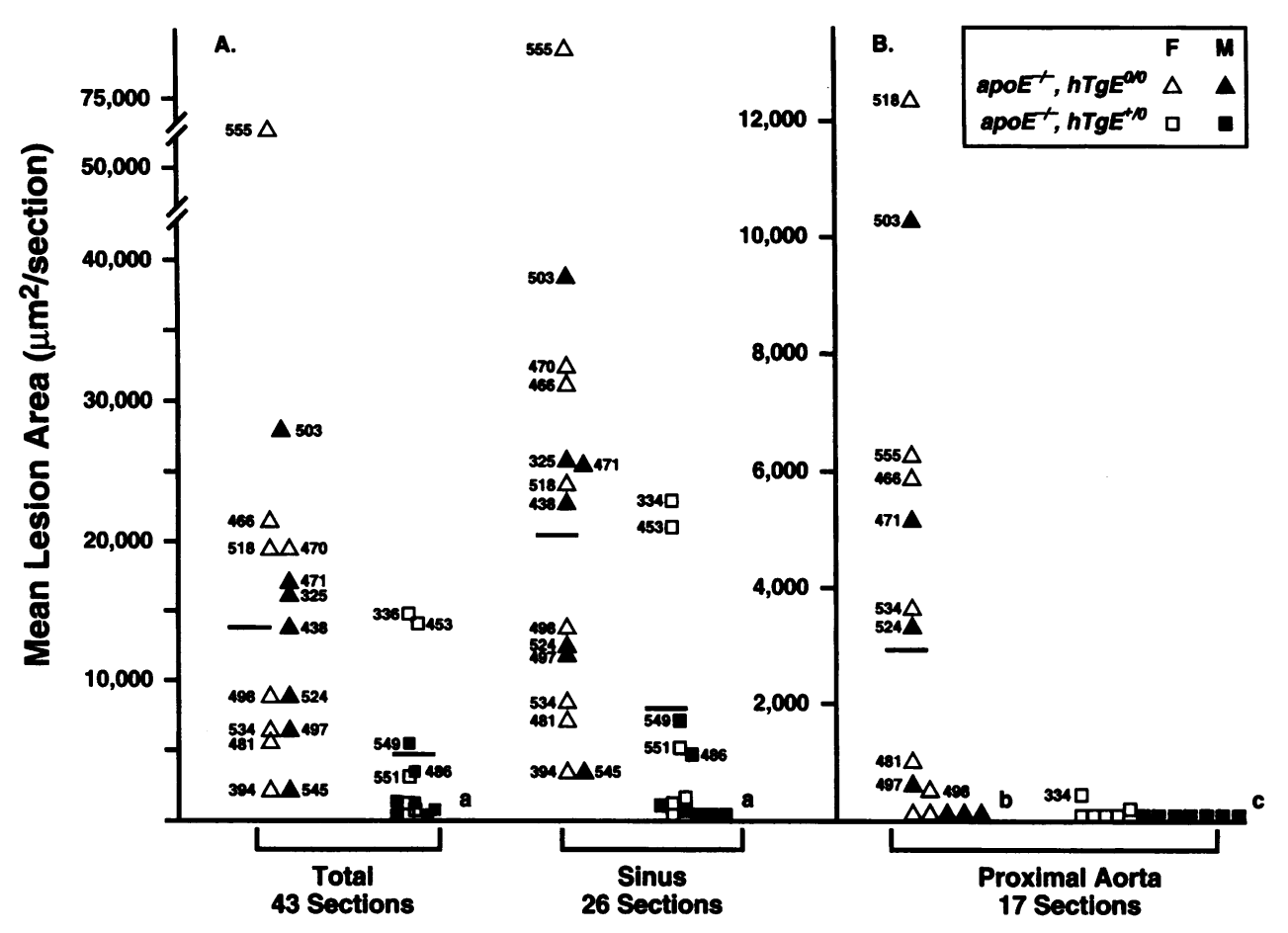

Figure 6. Quantitative analysis of atherosclerotic lesions in apo$E^{-/-}, h T g E^{0 / 0}$ mice (eight females, $\Delta$, and seven males, $\Delta)$ and in apo- $E^{-/-}, h T g E^{+/ 0}$ mice (six females, $\square$, and seven males, $\square$ ). A total of 43 sections for each mouse (26 from the aortic sinus and 17 from the proximal aorta) was analyzed. The area of intimal Oil Red O-positive (neutral lipiddelineating lesion) staining was measured in each section, and the mean lesion area per section was calculated. The values adjacent to the symbols are the plasma cholesterol concentration $(\mathrm{mg} / \mathrm{dl})$ for individual animals. The lesion areas for some of the animals are clustered, and therefore cholesterol values could not be reported in the figure. The cholesterol values for these mice are: cluster a, 423, 535, 473, 362, 482, 405, 461, and $449 \mathrm{mg} / \mathrm{dl}$; cluster b, 394, $470,438,545$, and $325 \mathrm{mg} / \mathrm{dl}$; cluster $\mathrm{c}$, the same as cluster a,

with the addition of four other animals with plasma cholesterol levels of $453,551,549$, and $486 \mathrm{mg} / \mathrm{dl}$. The mean lesion area values per section for the entire aortic root, for the sinus, and for the proximal aorta were $13,600 \pm 800 ; 20,600 \pm 1,200$; and $2,900 \pm 300 \mu \mathrm{m}^{2}$ in the $a p o E^{-1-}, h T g E^{0 / 0}$ animals and 4,800 $\pm 500 ; 7,700 \pm 800$; and $40 \pm 20 \mu \mathrm{m}^{2}$ in the apo- $E^{-/-}, h \mathrm{TgE}^{+/ 0}$ animals hemizygous for expression of human apoE in macrophages $(P<0.0001)$. The areas are reported as $\mu \mathrm{m}^{2} \pm$ SEM. The horizontal lines represent the mean value of lesion area for each group of mice.

plasma lipoprotein fractions were essentially superimposable. The concentrations of cholesterol in VLDL (fractions 16-19) and HDL (fractions 29-35) in the $a p o E^{-1-}, h T_{g} E^{0 / 0}$ (control) animals were $360 \pm 60$ and $42 \pm 14 \mathrm{mg} / \mathrm{dl}$, respectively. In the $a p o E^{-1-}, h T g E^{+/ 0}$ animals, the VLDL and HDL cholesterol levels were $328 \pm 44$ and $48 \pm 11 \mathrm{mg} / \mathrm{dl}$, respectively. Thus, the low-level expression of human apoE by macrophages did not appreciably influence the plasma lipoprotein distribution in the animals selected for the atherosclerosis study.

To determine whether the secretion of human apoE by macrophages could protect against the deposition of lipids and foam cell formation in the arterial wall, the extent of atherosclerosis in the aortic sinus and proximal aorta was determined in 43 Oil Red O-stained sections from each of the animals (Fig. 6) using a quantitative assay. The $a p o E^{-/-}, h \mathrm{TgE}^{+/ 0}$ animals had significantly $(P<0.0001)$ less atherosclerosis than the control apo $E^{-/-}, h T g E^{0 / 0}$ animals, whether the data were compared for the entire aortic root (Fig. $6 \mathrm{~A}$ ), for the aortic sinus (Fig. 6 $A$ ), or for the proximal aorta (normally quantitated in murine atherosclerosis studies) (Fig. $6 \mathrm{~B}$ ). The mean lesion area values per section for the total region examined, the sinus, and the proximal aorta for the $a p o E^{-1-}, h T g E^{0 / 0}$ animals were $13,600 \pm 800 \quad( \pm$ SEM $) \quad \mu \mathrm{m}^{2}, \quad 20,600 \pm 1,200 \mu \mathrm{m}^{2}, \quad$ and $2,900 \pm 300 \mu \mathrm{m}$, respectively. In the $a p o E^{-1-}, h T g E^{+/ 0}$ animals, these values decreased dramatically to $4,800 \pm 500,7,700 \pm 800$, and $40 \pm 20 \mu \mathrm{m}^{2}$, respectively. Both groups of mice have the same genetic background, C57BL/6 $\times 129 / \mathrm{J} \times \mathrm{ICR}$.

The extent of atherosclerosis also was compared in male and female mice. The female mice had more extensive atherosclerotic lesions than male littermates. The extent of atherosclerosis was significantly reduced in both male and female animals by expression of human apoE. In the males, the mean lesion area for the aortic root was $11,500 \pm 1,000$ ( \pm SEM) $\mu \mathrm{m}^{2}$ in the $a p o E^{-1-}, h T g E^{0 / 0}$ and $1,100 \pm 200 \mu \mathrm{m}^{2}$ in the $a p o E^{-1-}, h T g-$ $E^{+/ 0}(P<0.0001)$. In the females, the mean lesion area was $15,500 \pm 1,300 \mu \mathrm{m}^{2}$ in the $a p o E^{-1-}, h T g E^{0 / 0}$ and $9,000 \pm 1,000$ $\mu \mathrm{m}^{2}$ in the $a p o E^{-1-}, h T_{g} E^{+/ 0}(P<0.0002)$.

To verify that human apoE was produced in the arterial wall, sections of aorta from transgenic animals with significant lesions were analyzed for the presence of human apoE by immunocytochemistry (Fig. 7). Human apoE was clearly detectable in foam cells present within the lesions of the $a p o E^{-1-}, h T g$ $E^{+/ 0}$ transgenic animals (Fig. 7, $A-C$ ) but not in lesions from the control $a p o E^{-/-}, h T g E^{0 / 0}$ mice (Fig. $7 \mathrm{D}$ ). The lesions in the animals hemizygous for expression of human apoE consisted of fatty streaks with no fibrous caps. Apolipoprotein E-expressing foam cells were seen at the bases of the valve commisures (Fig. $7, A$ and $B$ ) and occasionally were observed below the internal elastic laminae (Fig. $7 \mathrm{~B}$ ). The lesions in $a p o E^{-1-}, h T g E^{0 / 0}$ mice were more advanced and widespread, had early fibrous capping, and contained necrotic cells and other debris.

Foam cells in these atherosclerotic lesions are primarily of macrophage origin. To verify that human apoE was produced by macrophages in the fatty lesions in $a p o E^{-1-}, h T g E^{+/ 0}$ transgenic mice, serial sections of the same lesion were immunostained for the presence of human apoE (Fig. 8, $A$ and $B$ ) or for the presence of murine macrophages (Fig. 8, $C$ and $D$ ). Human apoE was immunolocalized in lesion foam cells (Fig. 8, $A$ and $B$ ) in a pattern similar to that shown in Fig. 7. The underlying cells of the tunica media were not stained. The next serial section (panels $A$ and $C$ and panels $B$ and $D$ are consecutive serial sections) shows macrophage-specific staining in the same area in which apoE was expressed, demonstrating that the macrophages are the most likely source of the apoE. There is some 



Figure 7. Expression of human apoE by foam cells present in the lesion areas. Immunofluorescent images showing the presence of apoE atherosclerotic lesion macrophages from $a p o E^{-/-}, h T g E^{+/ 0}$ mice $(A-C)$ and the lack of expression in an atherosclerotic lesion from an $a p o E^{-/-}, h T g E^{0 / 0}$ mouse $(D)$. Cryostat sections from near the beginning of the proximal aorta were stained by indirect immunofluorescence cytochemistry using an antibody specific for human apoE. An FITC-conjugated secondary antibody was used to detect the primary antibody. Confocal immunofluorescence microscopy was used to image $(2 \mu \mathrm{m})$ optical sections of the lesions. $(A)$ An apoE-containing fatty streak including several foam cells. $(B)$ A similar fatty streak with the nuclei of the foam cells clearly resolved. Note the apoE-positive cells beneath the internal elastic lamina (running between the arrows). (C) Several macrophage-derived foam cells that are expressing human apoE, shown at a higher magnification. Note the polar juxtanuclear (arrow) and perinuclear fluorescence in the cell indicated by the arrow. This pattern of fluorescence indicates the presence of apoE in the secretory apparatus (Golgi apparatus and endoplasmic reticulum) of the cell. $(D)$ An atherosclerotic lesion from an $a p o E^{-/-}, h T g E^{0 / 0}$ mouse, shown as a negative control. As expected, human apoE is not detected in this section. This is the negative control for $A$ and $B$. Background fluorescence reveals the histology of the intimal lesion and part of the tunica media. (Bars $=10 \mu \mathrm{m}$.)

apoE that appears to be extracellular and associated with the matrix. The data therefore indicate the production of human apoE by macrophages in the arterial wall. Expression of human apoE in atherosclerotic lesion macrophages suggests that the production of apoE by these macrophages could contribute to the reduced lesion development noted in these animals.

\section{Discussion}

In this study, we have demonstrated that the expression of human apoE by macrophages reduced atherosclerosis in apoE-null mice despite the persistence of hypercholesterolemia. Human apoE was expressed in macrophages of transgenic animals, and they were cross-bred with murine apoE $E^{-/-}$mice to develop progeny that did not express murine apoE $\left(a p o E^{-/-}\right)$but were homozygous $\left(a p o E^{-/-}, h T g E^{+/+}\right)$or hemizygous (apo$E^{-1-}, h T g E^{+/ 0}$ ) for expression of human apoE in macrophages. Atherosclerosis was assessed in chow-fed 15-wk-old apo$E^{-1-}, h T g E^{+/ 0}$ mice and in apoE $E^{-1-}, h T g E^{0 / 0}$ littermates matched for plasma cholesterol concentration and lipoprotein profile. The data clearly demonstrate that the expression of human apoE in macrophages, in the absence of murine apoE, reduced atherosclerosis by 63 and $98 \%(P<0.0001)$ in the aortic sinus and proximal aorta, respectively.

Macrophage-specific expression was obtained using a construct that contained a 5.3-kb segment of the apoE gene under transcriptional control of the visna virus LTR. This promoter element previously had been shown to direct macrophage ex- 



Figure 8. Sequential cryostat sections of an atherosclerotic lesion from the proximal aorta of an apoE ${ }^{-/-}, h T g E^{+/ 0}$ transgenic mouse showing colocalization of immunofluorescence staining for human apoE ( $A$ and $B)$ and murine macrophages $(C$ and $D)$. Panels $A$ and $C$ and panels $B$ and $D$ show consecutive cryostat sections immunolabeled to detect apoE and a macrophage-specific antigen, respectively. Macrophage-specific staining is observed in the same area of the lesion and, in some cases in the same cells, as expression of human apoE. (Bar $=10 \mu \mathrm{m}$ for both panels.)

pression of a chloramphenicol acetyltransferase reporter construct in transgenic animals (25). A transgenic mouse line expressing human apoE in macrophages was established. These animals were crossed with murine apoE-null mice to create transgenic mice lacking mouse apoE and producing human apoE predominantly in macrophages. Peritoneal macrophages from these animals secreted human apoE, and human apoE was detected in macrophage-derived foam cells in atherosclerotic lesions. The apoE mRNA tissue distribution in the liver, lung, and spleen is consistent with macrophage production. In the liver, Kupffer cells appeared to be responsible for the production of human apoE, although a low level of expression by hepatocytes cannot be ruled out.
Interestingly, the expression of human apoE in macrophages resulted in low, but significant, levels of apoE in the plasma. The concentration of human apoE in the plasma of 30 apo$E^{-/-}, h \mathrm{TgE}^{+/ 0}$ animals ranged from 0.2 to $11 \mu \mathrm{g} / \mathrm{ml}$, much lower than the level of murine apoE normally present in nontransgenic animals (37). The plasma cholesterol concentration was inversely related to the amount of human apoE present in the plasma. Presumably, the entry of even small amounts of apoE into the plasma of the $a p o E^{-/-}, h T g E^{+/ 0}$ animals reduces the hyperlipidemia by mediating clearance of chylomicron and VLDL remnants, principally by hepatic receptor pathways. This hypothesis is supported by the finding that expression of rat apoE in transgenic mice reduces plasma cholesterol levels (38- 
40 ), as does the infusion of apoE into Watanabe heritable hyperlipidemic rabbits that are normally hypercholesterolemic (6, 41). Our results also are consistent with the recent work of Linton et al. (23), in which apoE expression was established in $a p o E^{-1-}$ animals by bone marrow transplantation, leading to a normalization of plasma lipid levels. However, the bone marrow transplant experiments showed a greater effect on suppression of plasma cholesterol than that observed in our studies. This enhanced effect on suppression of cholesterol levels probably was due to a higher level of apoE expression by the transplanted murine macrophages than the level of expression of the human apoE transgene obtained in our studies. In fact, we have shown that the level of secretion of human apoE by murine $a p o E^{-/-}, h \mathrm{TgE}^{+/ 0}$ macrophages is only $3-8 \%$ of the level of murine apoE secreted by normal macrophages. Alternatively, the murine apoE could be more effective in facilitating the clearance of mouse lipoproteins than human apoE, or the different genetic background of the mice used in our study could explain the different effect on plasma cholesterol.

The reduction of plasma lipoprotein levels alone could result in a reduction in the extent of atherosclerotic lesions. However, due to the wide variation in plasma cholesterol levels in the transgenic animals, we were able to select $a p o E^{-/-}, h T g E^{0 / 0}$ animals and $a p o E^{-/-}, h T g E^{+/ 0}$ littermates that possessed equivalent plasma cholesterol levels for evaluation of the effect of apoE expression by macrophages on accumulation of lipid in macrophage-derived foam cells in the arterial wall. The two groups of animals had similar lipoprotein profiles and nearly identical plasma concentrations of VLDL and HDL. Nonetheless, the $a p o E^{-1-}, h T g E^{+/ 0}$ animals did not develop significant atherosclerotic lesions in their proximal aorta, although their plasma lipid levels $(\sim 450 \mathrm{mg} / \mathrm{dl})$ were sufficient to cause the formation of extensive lesions in apoE ${ }^{-1-}, h T g E^{0 / 0}$ littermates $(15,16)$. In agreement with previous reports $(36,42,43)$, we also showed that female mice develop more extensive atherosclerosis than their male littermates in both the mice lacking human apoE and the mice expressing human apoE. These studies demonstrate for the first time that macrophage-specific expression of apoE markedly retards atherosclerosis in hypercholesterolemic animals independently of gross changes in circulating plasma lipoproteins. However, we cannot rule out the possibility that the human apoE circulating in the plasma may have an undetected effect on lipoprotein composition or metabolism that could contribute to the reduced susceptibility to atherosclerosis. Our studies differ significantly from those recently published by Linton et al., in which repopulation of previously irradiated $a p o E^{-1-}$ animals with bone marrow cells expressing apoE resulted in total normalization of plasma lipid levels and reduced atherosclerosis, as would be expected (23). Reduced atherosclerosis also was observed recently in transgenic mice expressing human apoE in a variety of tissues, including ectopic expression by endothelial and smooth muscle cells (cells that do not normally express apoE) of the arterial wall and in liver (24). In these latter studies, the effect of macrophage production of apoE could not be evaluated.

The mechanism by which the secretion of apoE by macrophages protects against the formation of atherosclerotic lesions is unknown. It has been postulated that $a p o E^{-/-}$mice develop atherosclerosis on a normal chow diet because of increased plasma levels of VLDL and intermediate density (atherogenic) lipoproteins and reduction in the plasma levels of HDL (antiatherogenic lipoproteins) $(15,16)$. In fact, two groups have reported that expression of human apoA-I increases HDL levels in apoE-null mice and reduces atherosclerosis $(44,45)$. In our study, VLDL, LDL, and HDL levels in the $a p o E^{-1-}, h \mathrm{TgE}^{+/ 0}$ animals were equivalent to those of $a p o E^{-/-}, h T g E^{0 / 0}$ mice, indicating that the protective effect of apoE is most likely not due to changes in plasma lipoproteins.

The protective effect of macrophage-derived apoE, therefore, may be due to an enhanced removal of cholesterol by lipoproteins from the cells of the arterial wall. Previously we have postulated a secretion-capture role for apoE (1). Apolipoprotein E secreted from cells interacts with cholesterol-rich lipoproteins in the environment of the cells, and the apoE-enriched particles participate in a local redistribution of the lipids to cells requiring lipids, or in a more global redistribution, the apoE targets the particles for receptor-mediated clearance (e.g., by the liver). This hypothesis is supported by the recent studies of Shimano et al. (24), in which enhanced efflux of cholesterol from the aortic wall into plasma was observed in animals expressing apoE in endothelial cells and smooth muscle cells of the arterial wall. In vitro studies have shown that secretion of apoE by macrophages in the presence of HDL can stimulate cholesterol efflux from cholesterol-enriched macrophages (46). It is possible that the human apoE secreted by macrophages in the arterial wall combines with HDL to form HDL enriched in apoE, which facilitates cholesterol efflux, as previously described (47-49). While plasma HDL levels are low, they may be sufficient, in the presence of macrophage-derived apoE, to mediate cholesterol efflux from macrophages and to be rapidly cleared from the plasma. Alternatively, apoE alone may also function in reverse cholesterol transport, as suggested by recent studies of Assmann and associates (50). In these studies they identified a plasma lipoprotein with $\gamma$ mobility, on agarose gels, that contained only apoE. This lipoprotein is present in human and normal mouse plasma, but it is absent in $a p o E^{-/-}$mouse plasma. It is secreted by peripheral cells, probably macrophages, and is a potent acceptor of cell-derived cholesterol (50). Additionally, apoE production by arterial wall macrophages may be modifying cytokines or growth factor modulation or activity, thus indirectly altering arterial wall foam cell formation. These possibilities remain to be explored.

In summary, we have shown that the expression of human apoE by macrophages is able to prevent the development of atherosclerotic lesions in hypercholesterolemic mice. This study demonstrates that only a low level of macrophage-specific expression of apoE, which is insufficient to have a significant impact on plasma lipid levels and lipoprotein distribution, has a highly significant impact on reducing atherosclerosis. These data suggest that targeted expression of apoE production by macrophages in the arterial wall could be a promising therapeutic approach for reducing foam cell formation and atherosclerosis.

\section{Acknowledgments}

We thank Brian Clark, Amy Corder, Stephen Gonzales, and John Carroll for graphics support, Don Haumant for preparation of the manuscript, and Dawn Levy for editorial support. We thank Dr. Robert Farese for helpful comments on the manuscript and Walter Brecht, Nianfeng Ge, and David Walker for expert technical assistance.

This work was supported in part by National Institutes of Health Program Project Grant HL-47660.

\section{References}

1. Mahley, R. W. 1988. Apolipoprotein E: cholesterol transport protein with expanding role in cell biology. Science (Wash. DC). 240:622-630. 
2. Weisgraber, K. H. 1994. Apolipoprotein E: structure-function relationships. Adv. Protein Chem. 45:249-302.

3. Pitas, R. E., T. L. Innerarity, K. S. Arnold, and R. W. Mahley. 1979. Rate and equilibrium constants for binding of apo-E $\mathrm{HDL}_{\mathrm{c}}$ (a cholesterol-induced lipoprotein) and low density lipoproteins to human fibroblasts: Evidence for multiple receptor binding of apo-E HDL . Proc. Natl. Acad. Sci. USA. 76:2311-2315.

4. Yamada, N., D. M. Shames, J. B. Stoudemire, and R. J. Havel. 1986 Metabolism of lipoproteins containing apolipoprotein B-100 in blood plasma of rabbits: heterogeneity related to the presence of apolipoprotein E. Proc. Natl. Acad. Sci. USA. 83:3479-3483.

5. Eisenberg, S., G. Friedman, and T. Vogel. 1988. Enhanced metabolism of normolipidemic human plasma very low density lipoprotein in cultured cells by exogenous apolipoprotein E-3. Arteriosclerosis. 8:480-487.

6. Mahley, R. W., K. H. Weisgraber, M. M. Hussain, B. Greenman, M Fisher, T. Vogel, and M. Gorecki. 1989. Intravenous infusion of apolipoprotein $\mathrm{E}$ accelerates clearance of plasma lipoproteins in rabbits. J. Clin. Invest. 83:21252130.

7. Mokuno, H., N. Yamada, H. Shimano, S. Ishibashi, N. Mori, K. Takahashi, T. Oka, T. H. Yoon, and F. Takaku. 1991. The enhanced cellular uptake of verylow-density lipoprotein enriched in apolipoprotein E. Biochim. Biophys. Acta. 1082:63-70.

8. Linton, M. F., R. Gish, S. T. Hubl, E. Bütler, C. Esquivel, W. I. Bry, J. K Boyles, M. R. Wardell, and S. G. Young. 1991. Phenotypes of apolipoprotein B and apolipoprotein E after liver transplantation. J. Clin. Invest. 88:270-281.

9. Driscoll, D. M., and G. S. Getz. 1984. Extrahepatic synthesis of apolipoprotein E. J. Lipid Res. 25:1368-1379.

10. Newman, T. C., P. A. Dawson, L. L. Rudel, and D. L. Williams. 1985 Quantitation of apolipoprotein E mRNA in the liver and peripheral tissues of nonhuman primates. J. Biol. Chem. 260:2452-2457.

11. Rosenfeld, M. E., S. Butler, V. A. Ord, B. A. Lipton, C. A. Dyer, L. K. Curtiss, W. Palinski, and J. L. Witztum. 1993. Abundant expression of apoprotein E by macrophages in human and rabbit atherosclerotic lesions. Arterioscler. Thromb. 13:1382-1389.

12. Mahley, R. W. 1983. Development of accelerated atherosclerosis. Concepts derived from cell biology and animal model studies. Arch. Pathol. Lab. Med. 107:393-399.

13. Mahley, R. W., T. L. Innerarity, S. C. Rall, Jr., and K. H. Weisgraber. 1984. Plasma lipoproteins: apolipoprotein structure and function. J. Lipid Res. 25:1277-1294.

14. Piedrahita, J. A., S. H. Zhang, J. R. Hagaman, P. M. Oliver, and N. Maeda. 1992. Generation of mice carrying a mutant apolipoprotein $E$ gene inactivated by gene targeting in embryonic stem cells. Proc. Natl. Acad. Sci. USA. 89:44714475 .

15. Plump, A. S., J. D. Smith, T. Hayek, K. Aalto-Setälä, A. Walsh, J. G. Verstuyft, E. M. Rubin, and J. L. Breslow. 1992. Severe hypercholesterolemia and atherosclerosis in apolipoprotein E-deficient mice created by homologous recombination in ES cells. Cell. 71:343-353.

16. Zhang, S. H., R. L. Reddick, J. A. Piedrahita, and N. Maeda. 1992 Spontaneous hypercholesterolemia and arterial lesions in mice lacking apolipoprotein E. Science (Wash. DC). 258:468-471.

17. Reddick, R. L., S. H. Zhang, and N. Maeda. 1994. Atherosclerosis in mice lacking apo E. Evaluation of lesional development and progression. Arterioscler. Thromb. 14:141-147.

18. Nakashima, Y., A. S. Plump, E. W. Raines, J. L. Breslow, and R. Ross. 1994. ApoE-deficient mice develop lesions of all phases of atherosclerosis throughout the arterial tree. Arterioscler. Thromb. 14:133-140.

19. Davies, M. J., N. Woolf, P. M. Rowles, and J. Pepper. 1988. Morphology of the endothelium over atherosclerotic plaques in human coronary arteries. $\mathrm{Br}$. Heart J. 60:459-464.

20. Faggiotto, A., R. Ross, and L. Harker. 1984. Studies of hypercholesterolemia in the nonhuman primate. I. Changes that lead to fatty streak formation. Arteriosclerosis. 4:323-340.

21. Ross, R. 1993. The pathogenesis of atherosclerosis: a perspective for the 1990s. Nature (Lond.). 362:801-809.

22. Rosenfeld, M. E., T. Tsukada, A. M. Gown, and R. Ross. 1987. Fatty streak initiation in Watanabe heritable hyperlipemic and comparably hypercholesterolemic fat-fed rabbits. Arteriosclerosis. 7:9-23.

23. Linton, M. F., J. B. Atkinson, and S. Fazio. 1995. Prevention of atherosclerosis in apolipoprotein E-deficient mice by bone marrow transplantation. Science (Wash. DC). 267:1034-1037.

24. Shimano, H., J. Ohsuga, M. Shimada, Y. Namba, T. Gotoda, K. Harada, M. Katsuki, Y. Yazaki, and N. Yamada. 1995. Inhibition of diet-induced atheroma formation in transgenic mice expressing apolipoprotein $\mathrm{E}$ in the arterial wall. $J$. Clin. Invest. 95:469-476.

25. Small, J. A., C. Bieberich, Z. Ghotbi, J. Hess, G. A. Scangos, and J. E Clements. 1989. The visna virus long terminal repeat directs expression of a reporter gene in activated macrophages, lymphocytes, and the central nervous systems of transgenic mice. J. Virol. 63:1891-1896.

26. Hess, J. L., J. E. Clements, and O. Narayan. 1985. Cis- and trans-acting transcriptional regulation of visna virus. Science (Wash. DC). 229:482-485.

27. Gabuzda, D. H., J. L. Hess, J. A. Small, and J. E. Clements. 1989
Regulation of the visna virus long terminal repeat in macrophages involves cellular factors that bind sequences containing AP-1 sites. Mol. Cell Biol. 9:2728-2733.

28. Hogan, B., F. Costantini, and E. Lacy. 1986. Manipulating the Mouse Embryo. A Laboratory Manual. Cold Spring Harbor Press, Cold Spring Harbor, NY. 332 pp.

29. McLean, J. W., N. A. Elshourbagy, D. J. Chang, R. W. Mahley, and J. M Taylor. 1984. Human apolipoprotein E mRNA. cDNA cloning and nucleotide sequencing of a new variant. J. Biol. Chem. 259:6498-6504.

30. Ji, Z.-S., S. J. Lauer, S. Fazio, A. Bensadoun, J. M. Taylor, and R. W Mahley. 1994. Enhanced binding and uptake of remnant lipoproteins by hepatic lipase-secreting hepatoma cells in culture. J. Biol. Chem. 269:13429-13436.

31. Simonet, W. S., N. Bucay, R. E. Pitas, S. J. Lauer, and J. M. Taylor. 1991. Multiple tissue-specific elements control the apolipoprotein E/C-I gene locus in transgenic mice. J. Biol. Chem. 266:8651-8654.

32. Lee, S.-H., P. M. Starkey, and S. Gordon. 1985. Quantitative analysis of total macrophage content in adult mouse tissues: immunochemical studies with monoclonal antibody F4/80. J. Exp. Med. 161:475-489.

33. Rall, Jr., S. C., K. H. Weisgraber, and R. W. Mahley. 1986. Isolation and characterization of apolipoprotein E. Methods Enzymol. 128:273-287.

34. Horie, Y., S. Fazio, J. R. Westerlund, K. H. Weisgraber, and S. C. Rall, Jr. 1992. The functional characteristics of a human apolipoprotein E variant (cysteine at residue 142) may explain its association with dominant expression of type III hyperlipoproteinemia. J. Biol. Chem. 267:1962-1968.

35. Fazio, S., Z. Yao, B. J. McCarthy, and S. C. Rall Jr. 1992. Synthesis and secretion of apolipoprotein $\mathrm{E}$ occur independently of synthesis and secretion of apolipoprotein B-containing lipoproteins in HepG2 cells. J. Biol. Chem. 267:6941-6945.

36. Purcell-Huynh, D. A., R. V. Farese, Jr., D. F. Johnson, L. M. Flynn, V. Pierotti, D. L. Newland, M. F. Linton, D. A. Sanan, and S. G. Young. 1995. Transgenic mice expressing high levels of human apolipoprotein B develop severe atherosclerotic lesions in response to a high-fat diet. J. Clin. Invest. 95:2246-2257.

37. Lusis, A. J., B. A. Taylor, D. Quon, S. Zollman, and R. C. LeBoeuf. 1987 Genetic factors controlling structure and expression of apolipoproteins B and $\mathrm{E}$ in mice. J. Biol. Chem. 262:7594-7604.

38. Shimano, H., N. Yamada, M. Katsuki, K. Yamamoto, T. Gotoda, K. Harada, M. Shimada, and Y. Yazaki. 1992. Plasma lipoprotein metabolism in transgenic mice overexpressing apolipoprotein E. Accelerated clearance of lipoproteins containing apolipoprotein B. J. Clin. Invest. 90:2084-2091.

39. Shimano, H., N. Yamada, M. Shimada, N. Ohsawa, C. Fukazawa, Y. Yazaki, F. Takaku, and M. Katsuki. 1991. Hepatic and renal expression of ra apolipoprotein $\mathrm{E}$ under control of the metallothionein promoter in transgenic mice. Biochim. Biophys. Acta. 1090:91-94.

40. Shimano, H., N. Yamada, M. Katsuki, M. Shimada, T. Gotoda, K. Harada, T. Murase, C. Fukazawa, F. Takaku, and Y. Yazaki. 1992. Overexpression of apolipoprotein $\mathrm{E}$ in transgenic mice: marked reduction in plasma lipoprotein except high density lipoprotein and resistance against diet-induced hypercholesterolemia. Proc. Natl. Acad. Sci. USA. 89:1750-1754.

41. Yamada, N., I. Inoue, M. Kawamura, K. Harada, Y. Watanabe, H. Shimano, T. Gotoda, M. Shimada, K. Kohzaki, T. Tsukada, M. Shiomi, Y. Watanabe, and Y. Yazaki. 1992. Apolipoprotein E prevents the progression of atherosclerosis in Watanabe heritable hyperlipidemic rabbits. J. Clin. Invest. 89:706-711.

42. Paigen, B., P. A. Holmes, D. Mitchell, and D. Albee. 1987. Comparison of atherosclerotic lesions and HDL-lipid levels in male, female, and testosteronetreated female mice from strains C57BL/6, BALB/c, and C3H. Atherosclerosis. 64:215-221.

43. Paigen, B., A. Morrow, P. A. Holmes, D. Mitchell, and R. A. Williams. 1987. Quantitative assessment of atherosclerotic lesions in mice. Atherosclerosis. 68:231-240.

44. Pászty, C., N. Maeda, J. Verstuyft, and E. M. Rubin. 1994. Apolipoprotein AI transgene corrects apolipoprotein E deficiency-induced atherosclerosis in mice. J. Clin. Invest. 94:899-903.

45. Plump, A. S., C. J. Scott, and J. L. Breslow. 1994. Human apolipoprotein A-I gene expression increases high density lipoprotein and suppresses atherosclerosis in the apolipoprotein E-deficient mouse. Proc. Natl. Acad. Sci. USA. 91:9607-9611.

46. Mazzone, T., and C. Reardon. 1994. Expression of heterologous human apolipoprotein $\mathrm{E}$ by $\mathrm{J} 774$ macrophages enhances cholesterol efflux to $\mathrm{HDL}_{3} . J$. Lipid Res. 35:1345-1353.

47. Hayek, T., J. Oiknine, J. G. Brook, and M. Aviram. 1994. Role of HDL apolipoprotein E in cellular cholesterol efflux: studies in apo E knockout transgenic mice. Biochem. Biophys. Res. Commun. 205:1072-1078.

48. Gordon, V., T. L. Innerarity, and R. W. Mahley. 1983. Formation of cholesterol- and apoprotein E-enriched high density lipoproteins in vitro. J. Biol. Chem. 258:6202-6212.

49. Koo, C., T. L. Innerarity, and R. W. Mahley. 1985. Obligatory role of cholesterol and apolipoprotein $\mathrm{E}$ in the formation of large cholesterol-enriched and receptor-active high density lipoproteins. J. Biol. Chem. 260:11934-11943.

50. Huang, Y., A. von Eckardstein, S. Wu, N. Maeda, and G. Assmann. 1994. A plasma lipoprotein containing only apolipoprotein $\mathrm{E}$ and with $\gamma$ mobility on electrophoresis releases cholesterol from cells. Proc. Natl. Acad. Sci. USA 91:1834-1838 